\title{
Numerical Analysis of Influence of Large-Diameter EPB Shield Tunneling on Ground Deformation in Beijing Area
}

\author{
Tao Gong ${ }^{1, \text { a }}$, Xiuren Yang ${ }^{2}$, Chengzhi $\mathrm{Qi}^{1}$, Deyun Ding ${ }^{2, \mathrm{~b}}$ \\ ${ }^{1}$ Beijing University of Civil Engineering and Architecture, Beijing, China \\ ${ }^{2}$ Beijing Urban Engineering Design and Research Institute Co., Ltd., Beijing, China \\ a449060397@qq.com, bdyding2301@163.com
}

\begin{abstract}
Keywords: Large-diameter EPB shield, Tunneling, Three-dimensional finite element method,
\end{abstract} Ground deformation, Grouting pressure, Supporting pressure.

\begin{abstract}
A large-diameter earth pressure balanced (EPB) shield has been firstly used in the Beijing metro line 14 in China. In this paper, to take the experimental project of the metro line 14 as an engineering background, the tunneling process of the EPB shield with an outer diameter of $10 \mathrm{~m}$ was simulated using the three-dimensional finite element method. The numerical results show that the ground settlement mainly appears in three phases during the shield tunneling: before the arrival of shield, the arrival of shield and the grouting phase, and they take respectively $32 \%, 45 \%$ and $23 \%$ of the total settlement. During the backfill grouting, the soil deformation around the segments goes up in the normal direction of the segments with the increase of grouting pressure. However, as the grouting pressure decreases, the rebounding of ground deformation occurs. Only increasing the grouting pressure to control the ground deformation is not effective. The influence of supporting pressure in soil chamber on excavation soil disturbance is evident. When the supporting pressure is less than a half of earth press at rest, the excavation face may be not stable and collapse during the shield tunneling, however, when the supporting pressure is more than 2 times earth press at rest, the soil ahead of the shield cutter is obviously squeezed.
\end{abstract}

\section{Introduction}

With the rapid development of shield technology, more and more large-diameter shields have been introduced into practical projects. Recently, a large-diameter shield with an outer diameter of $10 \mathrm{~m}$ has been firstly used in the Beijing metro line 14. Finite element simulation of shield tunneling concludes many details. Some detail simulations (the over-cut of cutter, grouting pressure and the interaction between shield and soil) were still unreasonable in existed shield tunneling simulations [1-6]. The large-diameter shield tunneling mainly focused on the effect of supporting pressure in soil chamber on underground ventilation adit, but the grouting process was simplified [7].

The experimental project (from Dongfengbeiqiao Station to Futongbei Station) of the metro line 14 being taken as an engineering background, the tunneling process of the EPB shield with an outer diameter of $10 \mathrm{~m}$ has been simulated using the three-dimensional finite element method. The slope of the shield body, the over-cut of cutter, the interaction between the shield and soil and force jacks have been considered, and the grouting pressure and the supporting pressure have been analyzed in detail during the shield tunneling in this paper.

\section{Three-Dimensional Finite Element Simulation}

Model Description. The overburden depth above the shield tunnel is $15 \mathrm{~m}$, the diameter of the tunnel and the outer diameter of the shield are $10 \mathrm{~m}$, and the thickness and width of each shield tunnel segment ring are $0.5 \mathrm{~m}$ and $1.8 \mathrm{~m}$, respectively. According to research needs, the length (X-direction), width (Y-direction) and height (Z-direction) of three-dimensional finite element model are respectively $90 \mathrm{~m}, 65 \mathrm{~m}$ and 54m, as shown in Fig.1. 


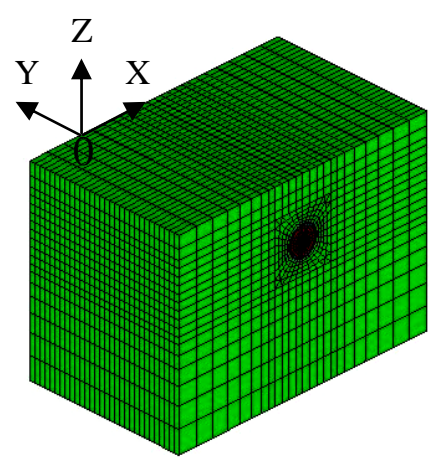

Fig.1 Three-dimensional finite element mesh

The soil parameters are derived from the survey report of the Beijing metro line 14. In order to facilitate the calculation and well reveal the universal change law in Beijing strata during the shield tunneling, the average value of the soil parameters are calculated by weighting average of each soil layer parameter. Soils are simplified as a homogenous soil. The Mohr-Coulomb model and the linear elastic model are adopted to simulate the characteristics of the soil and the structures respectively (Table 1).

Table 1 Physico-mechanical parameters

\begin{tabular}{|c|c|c|c|c|c|}
\hline Type & $\rho /\left(\mathrm{kg} \cdot \mathrm{m}^{-3}\right)$ & $\mathrm{E} /(\mathrm{MPa})$ & $\mu[-]$ & $\mathrm{c} /(\mathrm{kpa})$ & $\varphi /\left(^{\circ}\right)$ \\
\hline Soil & 1980 & 140 & 0.3 & 34 & 30 \\
\hline Segment & 2500 & 34500 & 0.2 & - & - \\
\hline Shield & 7500 & 210000 & 0.2 & - & - \\
\hline
\end{tabular}

\section{Simulation of Shield Tunneling}

Discrete Method for Shield Tunneling. The continuous steady-state construction process of shield tunneling is discretized to a step-by-step steady-state process, which is based on the transferring stiffness method during the simulation process [8] (Fig.2). The numerical analysis is completed by ABAQUS. Considering the interaction between the shield body and the soil, the frictional contact surfaces are set on the shield body and the surrounding soil.

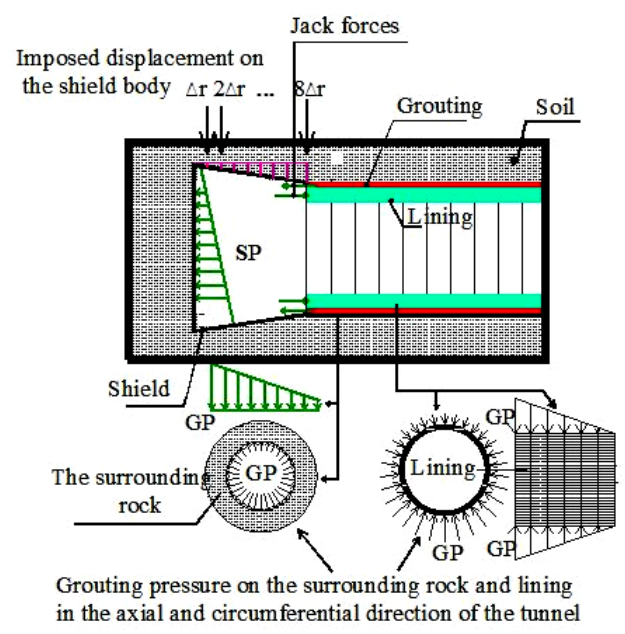

Fig.2 Schematic diagram of loads in shield tunneling process

Simulation of Slope of Shield Body and Over-Cut of Cutter. The diameter of the shield head is usually larger than the tail, so the shield body generally has a certain slope. The existence of the slop has great influence on ground settlement. To simulate the slope, the radial displacement $\triangle r$ is introduced which imposed on the pre-set shield body shell elements (Fig.2). Considering the slope and the over-cut of cutter, $\triangle r$ can be calculated by [8]:

$$
\Delta r=\frac{H_{l}(D-d)}{2 L_{S}}
$$

where $D$ is the diameter of the shield nose, $d$ is the diameter of the shield tail, $L_{\mathrm{S}}$ is the total length of the shield, $H_{l}$ is the width of a shield segment. 
Simulation of Supporting Pressure. Due to a great pressure difference at the tunnel crown and invert, the supporting pressure (SP) in a pressure chamber can be regarded as a trapezoidal distributed load (Fig.2) and calculated by:

$$
S P=\left(\sum_{i=1}^{\mathrm{n}} \rho_{i} g h_{i}\right) K_{0}
$$

where $\rho_{i}$ is the density of the $i$-th soil, $h_{i}$ is the thickness of the $i$-th soil, $K_{0}$ is the static earth pressure coefficient.

Simulation of Synchronous Grouting and Grouting Pressure. In practical engineering, the grouting material will change from the liquid state to solid state. The elastic modulus of the grouting material will gradually increase with the construction process, to some extent, which reflects the change of the characteristics of the grouting material in the numerical model (Fig.3). In the ideal state, the grouting pressure (GP) should be equal to the weight stress before the excavation of soil. Therefore, the GP should linearly increase from the top to the bottom of the tunnel. In the horizontal direction, the GP decreases while the grouting material strength increases gradually. The change of the GP is reflected, to some extent, through the gradual decrease to zero of grouting pressure applied to the surrounding rock and the segments with the construction step (Fig.2).
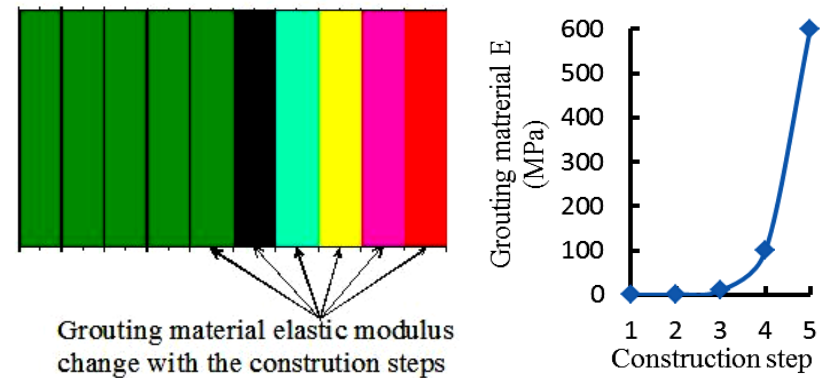

Fig.3 Schematic diagram of grouting material elastic modulus changes with the construction step

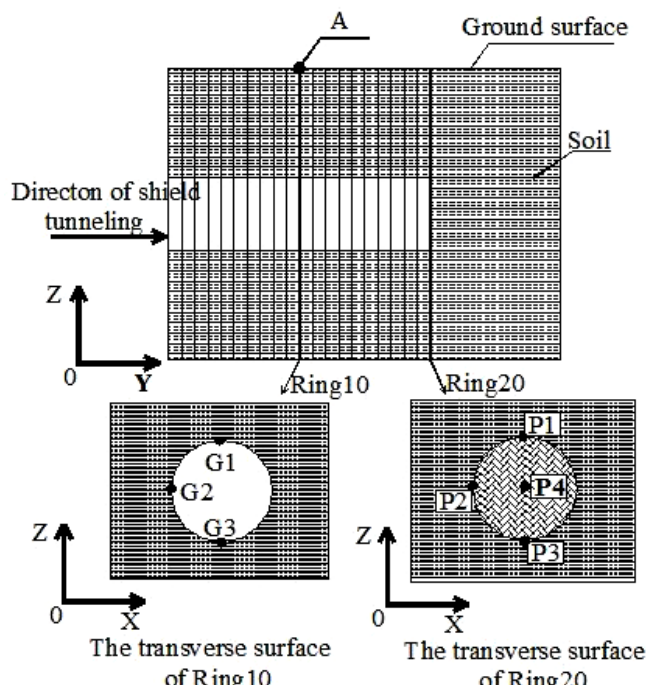

Fig.4 Schematic diagram of observation points

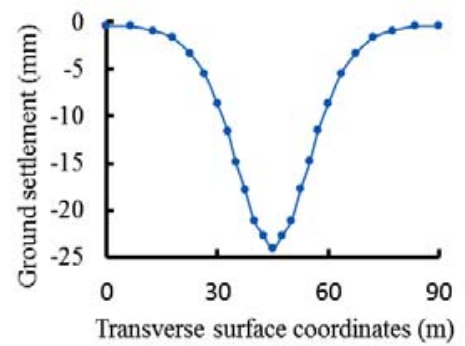

Fig.5 Transverse cross section ground surface displacement curve

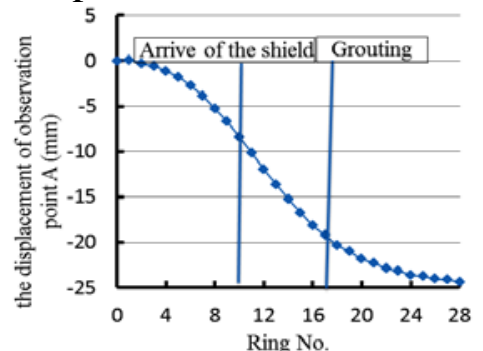

Fig.6 Observation point A displacement curve 


\section{Result Analysis}

Analysis of Ground Settlement. The influence of the normal shield tunneling on ground was studied firstly and surface displacement of the transverse cross section is given in Fig.5. The largest settlement is $24 \mathrm{~mm}$ which appears above the tunnel axis. The settlement law of the observation point A (Fig.4) on ground surface above Ring No10 in the shield construction is analyzed before and after the arrival of shield (Fig.6). The numerical results show that the settlement mainly appears in three phases during shield tunneling: before the arrival of shield, the arrival of shield and the grouting phase. In the first stage, the settlement is mainly caused by the low supporting pressure and the disturbance of the soil due to shield tunneling, and it takes $32 \%$ of the total settlement; In the second stage, a large settlement is produced due to the slope of the shield body and the over-cut of cutter, which takes $45 \%$ of the total settlement. In the last stage, the settlement which takes $23 \%$ of the total is induced by inadequate size of the grouting pressure and unsuitable strength of the grouting material and the segment.

Analysis of Grouting Pressure. Three observation points (G1、G2 and G3) on the transverse cross section of No.10 ring of the shield tunneling, where the deformations are predicted, are marked in Fig.4. In order to obtain the deformation law of the surrounding rock under the grouting pressure, five cases including different grouting pressures 0.5GP, 0.8GP, 1.0GP, 1.2GP and 1.5GP are considered in the simulation. The displacement of points G1, G2 and G3 are cleared before the grouting, so only the influence of the grouting process on the surrounding rock is studied. The deformations of three observation points (Z-direction of G1 and G3, X-direction of G2) are marked in Fig.7. The deformation curves show that the soil deformation around the segments goes up in the normal direction of the segments with the increase of grouting pressure. However, the displacements of the observation points rebound as the GP decreases which shows that compared to the displacement produced before the grouting, the displacement increases at G1 when the grouting pressure is 0.5GP, and that the displacement is essentially the same before and after the grouting when the grouting pressure is 1.5GP. The final displacements at G2 and G3 both increase in the normal direction of the segments in comparison to the displacement produced before the grouting. It shows that the greater the GP is, the larger the displacement will be. The top of the tunnel is in a more dangerous state than its both sides. The rebounding of observation points is due to the low early strength of the grouting material. Therefore, only increasing the GP to protect the surrounding rock is not effective, but will produce the repeated deformation in the surrounding rock. The early strength of the grouting material plays a vital role in the stability of the surrounding rock.

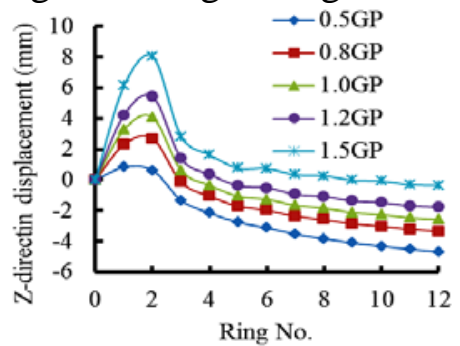

(a) Observation point G1

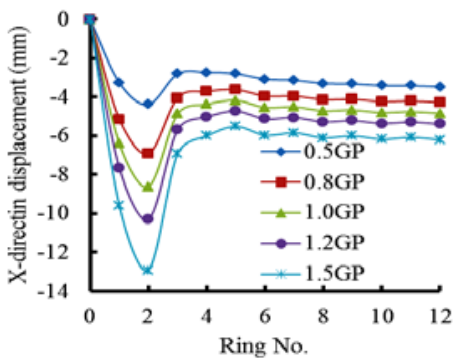

(b) Observation point G2

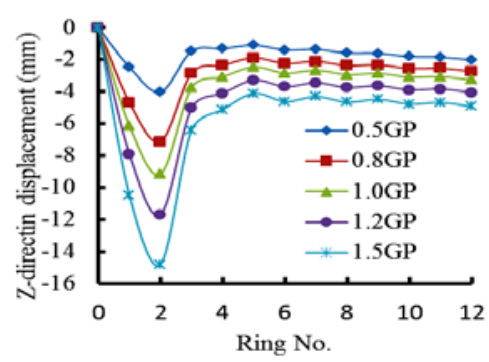

(c) Observation point G3

Fig.7 Displacements at observation points on No. 10 ring surrounding rock displacement curves

Analysis of Supporting Pressure. Four observation points (P1、P2、P3 and P4) on the transverse cross section of No.20 ring of the shield tunneling for measuring the deformations are marked in Fig.4. In order to obtain the excavation soil disturbance law during the shield tunneling under the supporting pressure, five cases including different supporting pressures 0.5SP, 0.8SP, 1.0SP, 1.5SP and 2.0SP are considered in the simulation. The displacement of the four observation points in Y direction when the shield tunneling approaches are shown in Fig.8. From the diagrams, the general tendency can be summarized as follows: the greater the SP is, the larger the affected area and the bigger the deformation will be. The minimum displacement of $\mathrm{P} 4$ is $-4 \mathrm{~mm}$ when the supporting pressure is $0.5 \mathrm{P}$ which shows that the SP is not large enough and the excavation face may be not stable and collapse. When the supporting pressure is close to $2 \mathrm{P}$, four observation points 
show deformations of 2 to $3 \mathrm{~mm}$ when the shield tunneling achieves No.10 Ring, but the points of P1, P2 and P3 show 7 to 8mm displacements and P4 Point $14 \mathrm{~mm}$ when the shield tunneling approaches which proves that the squeezing effect of the pressure of the front earth is remarkable and the affected area is large, which may cause the ground heaving. The maximum displacements of 4 observation points are less than $1 \mathrm{~mm}$ when the supporting pressure is $1 \mathrm{P}$. The soil is relatively stable at this level of pressure. Therefore, the ground surface and the soil ahead of the shield cutter must be strict monitored when the SP need to change during the shield tunneling.

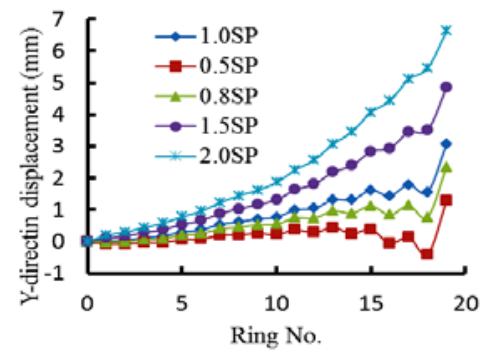

(a) Observation point P1

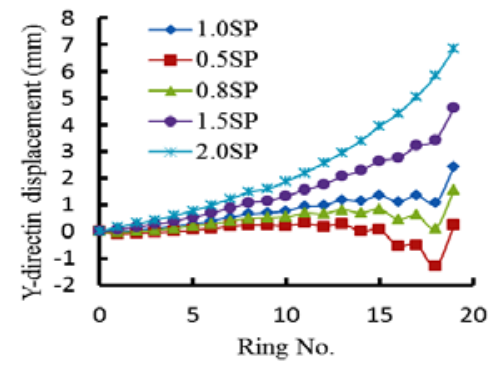

(c) Observation point P3

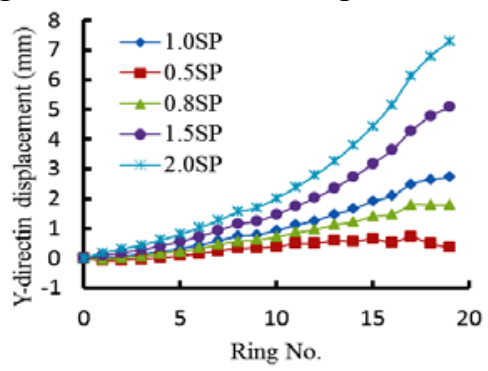

(b) Observation point P2

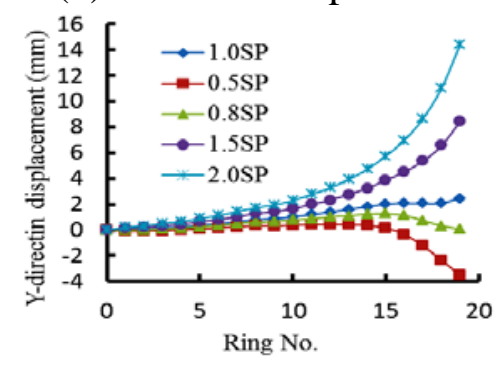

(d) Observation point P4

Fig.8 Displacements at observation points on No. 20 excavation face

\section{Conclusions}

1) The ground settlement mainly appears in three phases during shield tunneling: before the arrival of shield, the arrival of shield and the grouting phase which take respectively $32 \%, 45 \%$ and $23 \%$ of the total settlement.

2) During the backfill grouting, the soil deformation around the segments goes up in the normal direction of the segments with the increase of grouting pressure. However, as the grouting pressure decreases, the rebounding of ground deformation occurs. Only increasing the grouting pressure to control the ground deformation is not effective. The early strength of the grouting material plays a vital role in the stability of the surrounding rock.

3) The influence of supporting pressure in soil chamber on excavation soil disturbance is evident. When the supporting pressure is less than a half of earth press at rest, the excavation face may be not stable and collapse during the shield tunneling, however, when the supporting pressure is more than 2 times earth press at rest, the soil ahead of the shield cutter is obviously squeezed. The ground and the soil ahead of the shield cutter must be strictly monitored when the supporting pressure is changed during the shield tunneling.

\section{Acknowledgements}

This work is financially supported by the Technology Innovation Project of Beijing Urban Engineering Design and Research Institute Co., Ltd. (2010-07).

\section{References}

[1] K. Komiya, K. Soga, H. Akagi, T. Hagiwara, M.D. Bolton:,Soils and Foundations. Vol. 39(3) (1999), p. 37. 
[2] D.G. Lin, C.T. Tseng, N. Phienwej, S. Suwansawat: Journal of the Southeast Asian Geotechnical Socity. Vol. (31) (2002), p. 13.

[3] M.Q. Wang, S.H. Chen: Chinese Journal of Rock Mechanics and Engineering. Vol. 21(2) (2002), p.228.

[4] K.M. Lee, R.K. Rowe: Computers and Geotechnics. Vol. 2(2) (1990), p. 111.

[5] W.Q. Ding, Z.Q. Yue, L.G. Tham: International Journal for Numerical and Analytical Methods In Geomechanics. Vol. 28 (2004), p. 57.

[6] N. Yu, H.H. Zhu: Rock and Soil Mechanics. Vol. 25(8) (2004), p. 1330

[7] D.Y. Ding, X. R. Yang, W. D. Lu, W. N. Liu and M. Yan: International Conference on Electric Technology and Civil Engineering. Vol.1 (2011), p. 214.

[8] J.Q. Shen, X. L. Jin, J. Y. Wang: Journal of Shanghaijiaotong University. Vol. 42(8) (2008), p.1296. 